\title{
Places \& Spaces: A Critical Analysis of Cancer Disparities and Access to Cancer Care Among First Nations Peoples in Canada.
}

\author{
Tara C. Horrill ${ }^{1}$, Josée G. Lavoie², Donna Martin ${ }^{1}$, Annette S. H. Schultz ${ }^{1}$ \\ ${ }^{1}$ College of Nursing, Rady Faculty of Health Sciences, University of Manitoba ${ }^{2}$ Department of \\ Community Health Sciences, College of Medicine, Rady Faculty of Health Sciences, University of \\ Manitoba.
}

Cite as: Horrill, T., Lavoie, J., Martin, D. \& Schultz, A. (2020). Places \& Spaces: A Critical Analysis of Cancer Disparities and Access to Cancer Care Among First Nations Peoples in Canada. Witness: The Canadian Journal of Critical Nursing Discourse, Vol 2(2), 104-123. https//:doi.10.25071/2291-5796.62

\begin{abstract}
Despite advancements in health care and research, health inequities and disparities among First Nations (FN) Peoples in Canada are well documented and continue to grow. Cancer now is a leading cause of death among FN Peoples. Many factors contribute to cancer disparities, but FN Peoples face unique challenges in accessing healthcare. In this critical review and analysis, we explore potential links between cancer disparities and inequitable access to cancer care among FN Peoples. We do so through a postcolonial lens, with the aim of exposing and resisting the ongoing influences of colonialism. We argue that FN Peoples experience difficulty accessing cancer services in several 'places' of care throughout the cancer continuum and that notable 'spaces' or gaps emerge both within and between these 'places' of care, which contribute to cancer disparities among FN Peoples. These gaps in care, resulting from jurisdictional ambiguities, geographical location, unsafe social spaces, and marginalization of FN Peoples' ways of knowing, can be linked to colonial and neocolonial policies and ideologies. We aim to challenge discourses that attribute growing cancer disparities among FN Peoples in Canada solely to increases in 'risk factors' by drawing attention to these broader structural influences on health. Finally, we problematize the lack of attention to the structural conditions of health within nursing, and call on nurses to engage in a critical examination of how such gaps in care have been perpetuated by our individual and collective actions and inactions.
\end{abstract}

Keywords: health equity, health services accessibility, cancer, First Nations, Indigenous, nursing, health inequities 


\section{Prologue}

We wish to begin by acknowledging that as authors, we speak as nurses (TH, DM and $\mathrm{AS}$ ), and from the perspective of white settlers of European descent (all authors), and we recognize that along with these positions, comes a great degree of privilege and responsibility. Although we write as critical researchers, who bring extensive experience working with Indigenous Peoples, through clinical nursing practice, research, policy and health systems work, we do not speak for Indigenous Peoples, but only from our own experiences. Informing our work is knowledge from the fields of oncology nursing, rural nursing, critical care nursing and community health, and our experiences of witnessing inequities and injustices. We strive to engage in ongoing processes of critical self-reflection, examining our privileges and our complicity in the harms and injustices perpetuated towards Indigenous Peoples, while also seeking to bear witness to such injustices, and challenging others similarly positioned to do the same. While we endeavour to be allies to Indigenous Peoples and other groups experiencing social exclusion and structural violence, we take the position that allyship is a lifelong process involving ongoing self-examination, and that it is up to those we are attempting to support to determine if we have been allies in any given moment.

\section{Introduction}

The health and wellness of First Nations (FN) Peoples has been profoundly influenced by centuries of colonialism (Mitchell, Arseneau, \& Thomas, 2019). Evidence of these impacts is seen in the well documented health inequities and disparities among FN Peoples in Canada that persist despite significant healthcare advancements and access to a publicly funded healthcare system (Adelson, 2005). For example, cancer is now a growing concern among FN Peoples, and a leading cause of death (Canadian Partnership Against Cancer [CPAC], 2013). While many factors influence these growing disparities, the narratives informing our understanding of these disparities are narrowly focused on 'risk factors' (i.e., individual behaviors or 'lifestyle' choices), and epidemiological studies (i.e., high cancer incidence, and poor outcomes), despite evidence that FN Peoples experience difficulties accessing cancer care throughout their cancer journey (Horrill et al., 2019a; Horrill et al., 2018). However, examining the broader context of growing cancer-disparities, and in particular, the complexity FN Peoples are faced with in navigating and accessing cancer care - from screening through to palliative care - opens space to consider alternative influences on cancer disparities that extend the narrative beyond risk factors.

As the largest group of healthcare professionals in Canada, nurses bear witness to the health and social impacts of inequity and injustice in their everyday practice (Falk-Rafael \& Betker, 2012). Many nurses have argued that as individuals and as a collective we are morally obligated to act on injustice and inequities (Falk-Rafael, 2005; McGibbon \& Lukeman, 2019; Weitzel et al., 2020), and that as a profession social justice is a "core disciplinary ethos superseding time and context" (Thorne, 2014, p. 79). McGibbon and Lukeman (2019) argue that nursing has recently seen a "resurgence of the political, a deliberative focus on social change, and a growing uneasiness with remaining neutral in the face of such pressing need" (p. 3). However, within nursing practice and education a significant gap exists between purported social justice values and action to redress injustice, that is rooted in colonizing and racializing 
discourses (Anderson et al., 2009;

McGibbon et al., 2014). Developing a

counter-narrative within nursing to support

practice and curriculum changes will involve

critical reflection and dialogue, and

corresponding action, on injustices and the roots of inequities (Anderson et al., 2009;

McGibbon et al., 2014).

In this critical review and analysis, we explore links between cancer disparities and poor access to cancer care for FN Peoples in Canada. We use the term 'First Nations Peoples' to refer to the original inhabitants of the land now called Canada, including 'status' and 'non-status' FN Peoples, and those living on and off reserve (where specific evidence or claims relate to one of these distinct groups, it will be noted). This analysis was conducted as part of the lead author's doctoral work (TH), in which the objective was to map key policies shaping FN Peoples' experiences when accessing cancer care and discuss healthcare gaps contributing to reported cancer-related disparities among FN Peoples. The objective of this paper is not to provide an exhaustive or systematic review of the literature (see Horrill et al., 2019a), but to critically review and analyze existing literature describing cancer among FN Peoples in Canada, including primary research studies (qualitative, quantitative and mixedmethods) and grey literature reports, and to challenge current narratives regarding cancer-related disparities among FN Peoples. We do so through a postcolonial theoretical perspective, which aims to "expose, resist and transform the continuing presence and influence of colonial processes" (McGibbon et al., 2014, p. 182). We agree with McGibbon and colleagues (2014) who suggest that "one of the most important starting points in working for social change to decolonize nursing is to embrace the fact that oppressions often flourish without nurses being able or willing to name their oppressive actions. Nurses support oppression when they actively participate in oppression; deny or ignore oppression; or recognize oppression, but take no action" (p. 187).

In this analysis we aim to disrupt the current narratives within healthcare broadly and nursing specifically, that attribute growing cancer disparities among FN Peoples in Canada to increases in risk factors or 'lifestyle choices' by drawing attention to other factors influencing these disparities. We begin with an overview of the policy context shaping access to healthcare and service delivery among FN Peoples in Canada and synthesize what is currently known about cancer-related disparities among FN Peoples in Canada. We then present two alternative ways of understanding cancer disparities - through attention to the 'places' and 'spaces' of care. We follow the trajectory of a patient through the typical 'places of care' in the cancer journey, exploring inequities in access to cancer screening, diagnosis, treatment, survivorship, and palliative care that may be contributing to cancer disparities. We then draw attention to the 'spaces' or gaps in cancer care along the journey that result from jurisdiction, geography, unsafe social spaces, and marginalization of FN Peoples ways of knowing. We argue that these 'spaces' or gaps in care are rooted in colonial policies and ideologies, thus challenging the 'risk factor' narrative. Finally, we problematize the lack of attention to the structural conditions of health within nursing and call on nurses to engage in a critical examination of how such gaps in care have been perpetuated by our individual and collective actions and inactions.

\section{Background}

\section{First Nations Healthcare in Canada: The Policy Context}

Very few policies exist to specifically guide healthcare service delivery in Canada; 
The Canadian Journal of Critical Nursing Discourse

See it. Speak it. Write it. Change it.

what does exist serves largely to establish jurisdictional and fiscal responsibility for FN Peoples' health (Lavoie, 2013; National Collaborating Centre for Aboriginal Health, 2011). The British North American Act (BNA) grants responsibility for healthcare to the provincial governments, however no specific provision was made regarding healthcare for FN in this Act (Waldram, Herring, \& Young, 2006). The Indian Act, a paternalistic, 'race'-based policy, gives the federal government the authority to specify who may 'qualify' to register as an Indian under the law (Allan \& Smylie, 2015). FN Peoples eligible for registration under the Act are referred to as 'registered' or 'status'; those that are not eligible for registration are referred to as 'non-status'. Services for status FN when accessed on-reserve (primarily public health and health promotion) are financed and administered through the federal government; services for isolated communities may also include primary healthcare and limited medical care (Lavoie, Forget, \& Browne, 2010). Healthcare services provided off reserve (such as hospital and specialist care) are funded partially by the provinces, and primarily delivered through regional health authorities, as they are for all other Canadians. The jurisdictional division of responsibilities has effectively created a parallel healthcare 'system' for status FN Peoples on-reserve (Lavoie et al., 2010). Moreover, these jurisdictional borders are ambiguous, appear to be increasing in complexity (Lavoie et al., 2015), and have tangible effects on access to healthcare, particularly for those status FN Peoples living on reserve.

\section{Cancer Disparities among First Nations Peoples}

Cancer is an important public health concern in Canada and will continue to be for the foreseeable future (CPAC, 2011b). Significant cancer disparities exist between
FN Peoples and non-FN Canadians. Trends among FN Peoples suggests that the incidence of cancer is rapidly rising - faster among FN Peoples than other Canadians (CPAC, 2011a, 2013; McGahan et al., 2017). Cancer stage at diagnosis, an important predictor of disease course and treatment options and indicator of the quality of and access to screening and early detection efforts (CPAC, 2015; Decker et al., 2016), is also concerning. FN Peoples are more likely to be diagnosed with 'late-stage' cancers than non-FN (Decker et al., 2016; Horrill et al. 2019b; Sheppard et al., 2010), which can result in limited, more invasive, or costly treatment. Cancer survival is significantly poorer among FN Peoples compared to non-FN (Erickson et al., 2015; McGahan et al., 2017; Nishri et al., 2015; Withrow et al., 2017).

Although epidemiological evidence begins to paint the picture, Adelson reminds us that "statistical data alone, however, only tell us the degree of health disparity and not enough about the causes and extent of the felt effects" (Adelson, 2005, p. 59).

Historically, cancer disparities among FN Peoples have been implicitly and explicitly attributed to 'lifestyle deficits', including diet, physical activity, alcohol consumption, smoking, obesity and sexual behavior (Elias et al., 2011). More recently, these cancer disparities are understood as multifactorial, resulting from differences in access to care, negative healthcare experiences including discrimination and racism leading to delays in care, socioeconomic factors, and the ongoing impact of colonialism (Horrill et al., 2019b; McGahan et al., 2017; Withrow et al., 2017).

\section{Places of Care: Accessing Cancer Care Throughout the Trajectory}

The cancer experience is often described as a journey or a path, and while each patient's journey is a unique experience, most patients will experience a trajectory 
Figure 1: The Cancer Journey

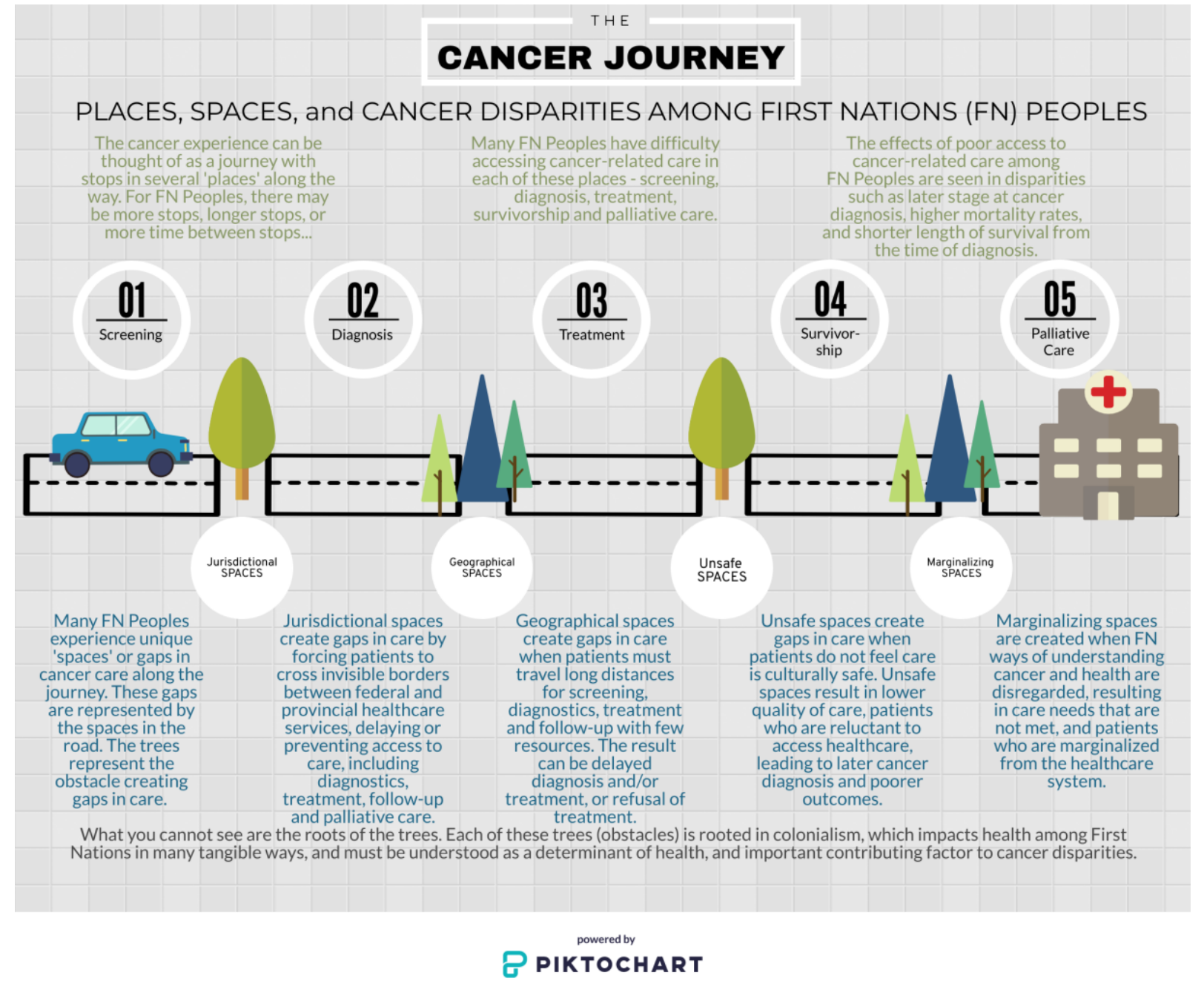

that includes cancer screening or a suspicion of cancer, diagnosis, treatment, and survivorship or palliative care. We have conceptualized these as 'places of care' which are both physical places, as in specific health services, and phases in the cancer trajectory (Fig 1). In this section, we briefly review the evidence concerning these 'places of care' and discuss how these might be related to cancer disparities.

\section{Cancer Screening}

Detecting cancer in its earliest stage through screening results in treatment that is more effective and less invasive, better quality of life, and improved survival. Although limited, data suggest that rates of cancer screening tend to be lower among FN Peoples (CPAC, 2013; Decker et al., 2015;

Demers et al., 2015). Within FN communities ("reserves"), a lack of information regarding cancer prevention, early warning signs and screening processes make screening difficult (Cancer Care Ontario [CCO], 2002; CancerCare Manitoba [CCMB], 2013; The Saint Elizabeth First Nations Inuit and Métis Program [SE], 2012). Distrust of Western medicine, family members' experiences with cancer, and lack of culturally safe screening environments have also been noted to discourage screening (CPAC, 2013). Limited local screening services and high turnover of healthcare providers within FN communities contribute 
The Canadian Journal of Critical Nursing Discourse

See it. Speak it. Write it. Change it.

to poor continuity of care and missed opportunities for cancer screening (Assembly of First Nations [AFN], 2009; CPAC, 2013; CCO, 2002; Maar et al., 2013).

The cost and complexity of travel (costly travel, childcare, unpaid employment absence) make accessing cancer screening services exceedingly difficult for some $\mathrm{FN}$ Peoples, especially those living outside of urban areas (Maar et al., 2013). Poor access to screening services and lower rates of screening are likely contributors to disparities in diagnosis, mortality, and survival.

\section{Cancer Diagnosis}

Cancer diagnosis is a pivotal 'place' in the cancer journey, and an important contributor to cancer outcomes: shorter time to diagnosis is associated with improved cancer outcomes (Neal et al., 2015), and significantly impacts survival (CPAC, 2015). Diagnoses of cancer are often made within the primary care setting, however difficulties in accessing primary care among FN Peoples both on and off reserve are widely acknowledged and multifaceted (CPAC, 2011a; Lavoie et al., 2010; SE, 2012).

Diagnostic testing is particularly challenging as medical travel is almost always required, and can delay cancer diagnosis (CCMB, 2013; Lavoie et al., 2016). For status FN Peoples living on reserve, delays in diagnosis are sometimes linked to "a federal transportation policy that will not subsidize transportation for preventative and diagnosis purposes" (Lavoie et al., 2016, p.7).

Complexities in communication and coordination between patients, primary care providers, diagnostic sites, and cancer specialists has also been noted to contribute to delayed referrals or missed follow-up (CPAC, 2013). Poor access to primary care may be contributing to later stage cancer diagnoses, requiring treatment that is more invasive and costly, or is limited to palliative care (CPAC, 2013; Lavoie et al., 2016).

\section{Cancer Treatment}

Upon suspicion or diagnosis of cancer, most patients are referred to an oncologist for cancer treatment - the next 'place' within the journey. Many FN Peoples face difficult decisions around treatment, which often requires travelling long distances or temporarily relocating to an urban center to access oncology care, resulting in lengthy time away from home and community, and a significant burden on patients and family (Lavoie et al., 2016). Although other Canadians living in rural and remote areas face similarly difficult decisions, FN Peoples experiences intersect with jurisdictional confusion, previous negative healthcare experiences, and a lack of culturally relevant support to add an additional layer of complexity; for these reasons, some FN Peoples decide against cancer treatment (CCMB, 2013; Lavoie et al., 2016). For status FN Peoples living on-reserve choosing to pursue treatment, this means crossing an invisible jurisdictional 'border' from care provided on-reserve (funded and/or provided by the federal government) to specialist care (funded and provided by provincial/territorial governments). Crossing this 'border' alone creates many challenges for FN Peoples. Moreover, significant gaps in cancer information have been noted, including information regarding treatment options, side effects, complications, and prognosis; moreover, this information is rarely culturally relevant or in FN languages (CPAC, 2011a, 2013; CCO, 2002; CCMB, 2013). Such barriers contribute to inequitable access to cancer treatment among FN Peoples, subsequently impacting cancer outcomes and contributing to cancer disparities.

\section{Survivorship \& Palliative Care}

Survivorship and palliative care, the next stages in the cancer journey, alleviate both physical and psychological symptoms 
The Canadian Journal of Critical Nursing Discourse

See it. Speak it. Write it. Change it.

associated with the diagnosis and/or treatment of cancer, however access to these services is seriously lacking among FN Peoples, particularly for those living on reserve (CPAC, 2013; Hammond et al., 2017; Olson et al., 2014). For many FN cancer survivors, supportive care is not available in or near their community, and appropriate information regarding cancer survivorship is difficult to access (Hammond et al., 2017; Olson et al., 2014).

Communication from tertiary care centers when patients are discharged home to their communities is poor, and challenges related to accessing primary care persist, resulting in inadequate access to basic follow-up care (CCMB, 2013; Olson et al., 2014). Access to palliative care among FN Peoples living on reserve has also repeatedly been acknowledged as a significant issue, and because of geography and jurisdiction, there are few or no palliative care services available in most FN communities. When palliative care services are available, they are generally not designed to accommodate FN practices around death and dying, and are not experienced as culturally safe (CPAC, 2013). When palliative care services are not available in the community, FN Peoples must travel long distances to regional or urban centers, which can be isolating and lonely (CPAC, 2013; CCMB, 2013).

\section{The Spaces Between: Gaps in Cancer Care}

While 'places of care' in the cancer trajectory are likely contributing to cancer disparities among FN Peoples and most certainly impact FN Peoples' experiences, notable 'spaces' emerge both between and within the 'places of care'. Here, we conceptualize 'spaces' in several ways. Jurisdictional 'spaces' represent gaps created theoretically by the division of governmental responsibility for status FN healthcare. These spaces create tangible gaps between healthcare provided by federal and provincial governments, and consequently, gaps in the cancer journey. Geographical 'spaces' refer to the physical spaces or distances between FN communities and the location of cancer services, creating gaps in care by virtue of geography. Social distance between FN Peoples and healthcare providers result in healthcare 'spaces' that are experienced as socially unsafe, often resulting in avoidance of care. Marginalizing 'spaces' are created epistemologically through hierarchies of knowledge, when FN ways of knowing, specifically those related to health and healing, are positioned as inferior to biomedical ways of knowing. Each of these 'spaces' can be seen throughout the cancer journey and can be linked to colonial ideologies and policies (Figure 1).

Colonialism can be understood as a system of exploitation based on rigid hierarchies and the construction of colonized (in many cases, Indigenous) Peoples as intrinsically inferior (Ashcroft, Griffiths, \& Tiffin, 1998). Browne (2001) defines ideology as "a set of closely related beliefs, attitudes or ideas characteristic of a societal group", which tend to perpetuate value-laden claims (p. 119). The ideology of 'race', or the genetic inferiority of certain groups, grew in tandem within colonialism, and was used to justify colonial activities (Ashcroft et al., 1998). The healthcare system is an extension of the colonial system, in which the colonial relationship is often obscured or justified based on potential 'gains' (i.e., treatment of disease) for FN Peoples, whether extended or not.

\section{Jurisdictional Spaces}

The multi-jurisdictional nature of cancer services for FN Peoples makes accessing cancer care particularly challenging, and the fragmented nature of cancer care creates spaces or gaps between the places of care (CPAC, 2011a, 2013; Tobias et al., 2020); 
The Canadian Journal of Critical Nursing Discourse

See it. Speak it. Write it. Change it.

this is especially true for status FN Peoples living on reserve. Current policies further entrench jurisdictional gaps rather than alleviate them and serve as barriers to accessing healthcare (Lavoie et al., 2010). Within the cancer journey, several government-funded providers may be involved, each with their own priorities and interests (i.e., oncology clinics, specialists, family physicians, Tribal Councils, First Nation community clinics). Poor cooperation between levels of government and lack of strategic leadership have resulted in little progress in cancer control (AFN, 2009). Moreover, jurisdictional ambiguities are difficult to resolve, and rely on the accommodation of individuals within government in the absence of clear policy guidelines for FN health (Cook, 2003). For example, the Non-Insured Health Benefits (NIHB, a federally funded program providing coverage to status FN Peoples for medical and health-related expenses not covered under provincial health insurance), and specifically, the medical transportation policy (a component of NIHB providing transportation for FN Peoples to access medically necessarily health services not available in their community of residence) exist for the purposes of providing resources to support access to health services, including cancer services. However, it is often individuals (managers or clerks) who are left to interpret and enforce broadly defined and ambiguous policy objectives, and gaps in care arise as a result of these individuals' understanding of jurisdictional obligations (Lavoie et al., 2015). Most concerning, eligibility for medical transportation and other resources is rarely the issue; rather, priorities include cost containment and avoiding establishing precedence (Lavoie et al., 2015). Lavoie et al (2015) note that this context "fuels rather than alleviates tensions and perpetuates an adversarial and politicized environment" in which access to care becomes compromised (p. 311). Rather than allowing for flexibility, maximizing access to healthcare, and focusing on overall efficiency, current trends appear to be increasingly focused on centralized decision-making, accountability, and rigidly defined federal and provincial jurisdictions (Lavoie \& Forget, 2008).

Beyond accessing care, communication across jurisdictions has repeatedly been documented as problematic, as previously discussed. Navigating this complex multijurisdictional system without 'falling through the cracks' is a considerable challenge; some FN cancer patients report experiencing 'logistical fatigue' which significantly impacts on their ability to access care (Lavoie et al., 2016).

Consequences of jurisdictional gaps include delayed cancer diagnoses, delayed specialist referral, delayed cancer treatment, poor follow-up care, and patients who abandon cancer treatment entirely (Lavoie et al., 2016; SE, 2012).

Jurisdictional spaces are a direct result of policy and legislation. The division of responsibilities outlined in the BNA Act and Indian Act began the centuries-long debate over the jurisdictional responsibility for $\mathrm{FN}$ health. Rooted in racist colonial ideology, such legislation establishes invisible jurisdictional borders with devastating effects on the health of FN Peoples and access to healthcare (Reading, 2015).

\section{Geographical Spaces}

The geographical location of many FN communities creates tangible gaps between a patient's home and the place where specialized cancer care is available. de Leeuw (2016) argues that geography is not a neutral or static entity, but rather an active determinant of health: "where we are and how we are in that space matters" (p. 93). Delivery of comprehensive primary care services to rural and remote FN communities is challenging, and the healthcare services provided are limited. As a result, FN Peoples 
The Canadian Journal of Critical Nursing Discourse

See it. Speak it. Write it. Change it.

living in these communities are required to travel for virtually all cancer services, resulting in fewer opportunities for cancer screening, late diagnoses, and poor outcomes (CPAC, 2013; Reading, 2015). The sheer distance and mode of transportation can make travel onerous, uncomfortable or dangerous for patients who are ill or receiving cancer treatment, and for many patients, they must face these challenges alone, leaving the support of family and community behind during a particularly challenging time (CPAC, 2013). Because of restrictions on travel coverage for family members through NIHB, patients are left to advocate for their own needs while unwell and in an unfamiliar location (CPAC, 2013; Lavoie et al., 2016). As a result, some FN patients choose to forego or abandon cancer treatment entirely (Lavoie et al., 2016).

In Canada, the Medical Transportation Policy provides transportation funding for status FN Peoples to access medically necessary health services that are not available on reserve (including cancer screening, diagnostics and treatment), however, is repeatedly acknowledged as complicating access to a range of cancerrelated services among FN Peoples, and is often denied in the context of cancer screening (CCMB, 2013; Lavoie et al., 2015; Lavoie et al., 2016; Maar et al., 2013; Olson et al., 2014; SE, 2012). Eligibility criteria seem to be unclear and fluid at times, with transportation denied for reasons not stated in the Policy (Lavoie et al., 2015). These seemingly arbitrary decisions must be understood within the context of FN Peoples' lives and experiences, where geographical location and access to transportation intersect with socio-historical context of colonial government relationships, and experiences of discrimination and dismissal of health concerns (Lavoie et al., 2016). Requests for medical transportation must also be seen within the context of ambiguous jurisdictional boundaries, "where all agencies involved may understand the request as someone else's responsibility" (Lavoie et al., 2015, p. 310). Delays in cancer diagnosis and treatment related to geography and the Transportation Policy may be contributing to poorer cancer outcomes (Lavoie et al., 2016).

The geographical location of $\mathrm{FN}$ reserve communities stems directly from colonial policy and is entrenched in the Indian Act. FN homelands were appropriated, and communities forcibly relocated to 'reserve' lands controlled by the federal government and allocated to those identified as 'Indian' (Allan \& Smylie, 2015; Browne, Smye, \& Varcoe, 2005). Allan and Smylie (2015) note that "this removal to reserve lands began a system of segregation that would become the template for apartheid in South Africa" ( $p$. 10). More than a method of segregation, the Indian Act constructed a system of subjugation, designed to control, assimilate, and eliminate FN Peoples (Adelson, 2005). Geography intersects with jurisdiction to create differential access to care among FN themselves: while status FN Peoples are entitled to access federal resources including Non-Insured Health Benefits (such as medical transportation), many non-status FN and non-FN partners and children also live in reserve communities and experience similar socioeconomic and health conditions, yet are not entitled to these benefits. For FN Peoples, geographical location is more than simply a matter of rurality or remoteness many other Canadians live rurally or remotely - but is rooted in a colonial system that has shredded FN communities and ties to land that are so foundational to identity and wellness (de Leeuw, 2016). However, close geographical proximity to cancer services does not necessarily guarantee access to those services, as services alone do not ensure health; moreover, access to services does not guarantee that those services are responsive to needs of $\mathrm{FN}$ 
The Canadian Journal of Critical Nursing Discourse

See it. Speak it. Write it. Change it.

Peoples (Adelson, 2005). FN Peoples continue to experience gaps in care related to socially unsafe care, regardless of 'status' or geographical location.

\section{Unsafe Spaces}

Common understandings of cancer within FN communities, and previous negative experiences when accessing healthcare services create social distance between patients and healthcare providers, and healthcare spaces that are experienced by FN as culturally and socially unsafe. Although the word 'cancer' is generally steeped in fear, this is particularly true among FN Peoples as it is perceived as a death sentence (Hammond et al., 2017; Loppie \& Wien, 2005). Although some would suggest that fears of cancer are unfounded given recent medical advances, Hammond et al (2017) note that "perceptions of cancer's fatality are aligned with the typical cancer trajectory within First Nations communities in Canada, where inaccessibility and inadequacy of services across the cancer continuum lead to later stage diagnoses and more deaths" (p. 196). Within this unsafe space of fear and uncertainty, some FN Peoples avoid talking about cancer and addressing health concerns for fear of a cancer diagnosis (CPAC, 2011a; Hammond et al., 2017).

Negative experiences and encounters with the healthcare system and healthcare providers are widespread among FN Peoples and well documented. Distrust in government provided healthcare services and healthcare providers, and fast-paced clinical environments that do not allow for establishing trusting relationships between providers and patients amplify these unsafe spaces and contribute to gaps in care (CCO, 2002; Wakewich et al., 2016). Biomedical discourses that attribute cancer primarily to 'lifestyle' choices or behavioral risk factors, which convey blame and personal responsibility, leave little room for alternative explanations. Discourses privileging genetic and biological causes of cancer disparities among FN Peoples seriously underestimate the role of social and structural determinants of health (Vasilevska et al., 2012). Entrenched in biomedicine are neoliberal philosophies of individualism and egalitarianism, which assume that health is entirely an individual responsibility, and that individuals have equal life opportunities and resources available to make healthy; failure to achieve health or access healthcare is construed as a personal deficit (Browne, 2001). Within the realities of unsafe spaces, patients experience fear, distrust, and dismissal, and become increasingly reluctant to seek timely care for their health concerns; consequently, cancer diagnoses are delayed, and treatment options become limited (CPAC, 2013; Lavoie et al., 2016; Tobias et al., 2020).

The relationships between FN Peoples and government-provided healthcare services must be understood within the context colonialism, where distrust of healthcare services stems from historical trauma. In Canada, historical trauma among FN Peoples is rooted in dislocation from lands and forced relocation to reserve lands, forced attendance at residential schools, and other policies aimed at assimilating and eliminating FN Peoples (Allan \& Smylie, 2015). Residential schools have seriously damaged the lives and culture of FN, and have had direct, indirect and long-lasting effects on mental and physical health (Waldram et al., 2006). Negative experiences and encounters with healthcare providers must also be seen with the context of colonialism and are similarly rooted in ideologies of the inferior 'other'. Colonial ideology rears its ugly head in popular social discourses that construct FN Peoples as lazy, alcoholics, dependent on the state, and as "getting everything for free" (Browne, 2005, p. 182). These discourses are taken up by some healthcare providers through 
racializing assumptions (attributing health and social problems to 'race'), and subsequently organize the attitudes, assumptions and actions of healthcare providers towards FN Peoples (Browne, 2005). Gaps in care ensue when FN Peoples do not access healthcare services because they do not feel safe.

\section{Marginalizing Spaces}

FN Peoples' access cancer care in spaces that marginalize FN Peoples' conceptions of cancer, healing, and wellness, resulting in unmet needs and lower quality of care (Garvey et al., 2020). Cancer is described as feeling the "presence of a stranger" among Anishinaabe FN (Hart-Wasekeesikaw, 1996). This stranger is described by some FN Peoples as a worm, bug, maggot, or germ-cell, and is understood to be 'eating away' at one's insides (Barkwell, 2005; Hart-Wasekeesikaw, 1996). FN Peoples' conceptualizations of health are fundamentally different from biomedical conceptualizations of health, incorporating interrelated dimensions of physical, spiritual, emotional and mental health, strong connections with land and community, and the honoring of relationships (Reading \& Wien, 2009; Walker \& Behn-Smith, 2015). In the hierarchy of knowledge, however, western (biomedical) conceptions of health, illness and cancer dominate, and create epistemological distance or 'space', pushing other ways of knowing to the margins. Walker and Behn-Smith (2015) note that within this hierarchy of knowledge, "the 'evidence-based' biomedical model implicitly renders Indigenous medicine and knowledge as less scientific and therefore dubious" (p. 245). The silo approach of treating body parts in isolation may not be well accepted among FN Peoples (CCO, 2002; Walker \& Behn-Smith, 2015), and many FN Peoples report that their emotional, mental, spiritual and social needs are not being met or even assessed by oncology providers, creating a significant gap in care (CPAC, 2013; Garvey et al., 2020).

For some FN Peoples, using the word 'cancer', or discussing death or dying can be inappropriate, and cause increased anxiety (CCMB, 2013). Some FN Peoples desire traditional healing, or an approach that blends biomedical and traditional healing, but many cancer centers do not have processes to accommodate this type of blended approach (CPAC, 2013; CCO, 2002). The lack of understanding among healthcare providers regarding traditional healing, or the view of such practices as ineffective or not 'evidence-based' risks further marginalizing Indigenous Knowledges and FN patients from the dominant healthcare system.

The dominance of biomedicine and marginalization of Indigenous Knowledges can be linked to imperialist ideology, or the assumption of European racial, intellectual and cultural superiority (Ashcroft et al., 1998). Colonialism (one particular expression of imperialism) sought to establish a hierarchy of knowledge and use that knowledge to exert power and domination (Smith, 2005). Western medicine played a key role in colonization, by rationalizing colonial activities as medical 'aid' (Kelm, 1998). Reading (2015) states that the role of western medicine was "instrumental in not only shaping ideas about Indigenous Peoples and their communities but in perpetuating a medical discourse that described them as inherently pathological, making the provision of healthcare a colonial obligation" (p. 7). Thus, healthcare in relation to FN Peoples in Canada has been shaped by centuries of colonial thinking that has marginalized Indigenous Knowledges of health and healing, and in the process has marginalized FN Peoples from the healthcare system (Adelson, 2005).

\section{Disrupting the Disparities Discourse}


The Canadian Journal of Critical Nursing Discourse

See it. Speak it. Write it. Change it.

Access to cancer care among FN Peoples is problematic throughout the cancer journey and is contributing to documented cancer disparities. Damaging ideologies and paternalistic policies have and continue to shape the lives and health of FN Peoples by constructing gaps in access to healthcare. Jurisdictional and geographical spaces can be linked to colonial policies reflected in the $B N A$ Act, and the Indian Act. These spaces are particularly problematic within the cancer journey, creating barriers to accessing high quality and timely cancer care. Unsafe and marginalizing spaces are rooted in colonial ideologies and social discourses, as well as policies that prioritize a biomedical and service delivery model of healthcare. By unpacking the role of places and spaces in contributing to cancer disparities among FN Peoples, we challenge the disparity discourse of racialized assumptions that FN Peoples are "inherently inferior and deficient" (Battiste \& Youngblood Henderson, 2012, p. 92). Reducing cancer disparities among FN Peoples must involve improving access to high quality, safe and timely cancer care. More importantly, rather than 'medicalizing' social problems by focusing on individuals and their 'deficits', a shift towards a whole systems approach, and attention at the structural level is necessary.

Structural inequities are those that are power-laden, systematically produced by, and embedded in, political, social and economic institutions (McGibbon, 2016). A structural perspective attends to the root causes of poor health; through this lens, access to care can be understood in its broadest sense, including the social, political, historical and economic conditions underpinning inequities in access to healthcare (Pauly, MacKinnon, \& Varcoe, 2009). Thus, rather than remaining fixated on epidemiological perspectives and growing cancer disparities, attention is also given to the broader systems of inequality that both create and sustain poor health.
What must be made explicitly clear is that such disparities have not developed in a vacuum, nor are they a result of biology or culture; rather, they are directly linked to colonial policies and institutions (Battiste \& Youngblood Henderson, 2012).

Attending to the structural determinants of health should be of importance to nurses, who witness the impacts of such inequities in their practice. McGibbon and Lukeman (2019) urge nurses to work "at the pointy edges of suffering and safety in peoples' lives, and yet go well beyond this suffering to disrupt structures that cause suffering in the first place" (p. 5). As nurses, therefore, we must begin to think of ourselves and of our profession as inherently political (Thorne, 2014), and work at both the individual or 'downstream' and the structural or 'upstream' levels (Falk-Rafael \& Betker, 2012). Strengths-based approaches to program development and research challenge 'deficit discourses' by focusing on existing assets, addressing root causes of illness, and promoting overall wellness, while ensuring programs and services are culturally tailored (Fogarty et al., 2018). Within nursing, however, a focus on structural determinants of health has not been sustained and is rarely seen in nursing education, yet such understanding is critical to disrupting the disparities discourse and to effectively redressing health inequities (Fogarty et al., 2018; McGibbon et al., 2014; van Herk, Smith, \& Andrew, 2011). Incorporating structural competency concepts - training clinicians to see the clinical and patient impacts of 'upstream' determinants of health - into professional nursing education would begin to help nurses to recognize, understand and address the structural roots of cancer disparities among FN Peoples in Canada (Metzl \& Hansen, 2014).

Yet the lack of attention to the structural conditions of health is a concerning example of moral bystanding - our intentional or 
The Canadian Journal of Critical Nursing Discourse

See it. Speak it. Write it. Change it.

unintentional, individual or collective inaction as nurses (McGibbon \& Lukeman, 2019). While the focus of this paper has been on disrupting the disparities discourse through attention at the systems as structural level, as nurses, we must ask ourselves how such disparities have been perpetuated by our individual and collective actions. How have we contributed to the creation of unsafe spaces through our unconscious beliefs? How have our unquestioned colonizing and racist assumptions about FN Peoples seeped into our actions and interactions? How are these assumptions embedded in and therefore transmitted through our nursing curricula and professional development? How have we furthered the construction of marginalizing spaces through our support of biomedicine and subjugation of Indigenous Knowledges? How have we been part of the problem through our moral bystanding or inaction? Cultural safety, anti-racism and trauma-and violence-informed care education are one path to developing a critical consciousness within nursing, and can enhance healthcare provider awareness of and responsiveness to racism, colonialism, and oppression as determinants of health and healthcare access (Browne et al., 2018; Kurtz et al., 2018; Levine, Varcoe, \& Browne, 2020; Yaphe, Richer, \& Martin, 2019). Integration of cultural safety and trauma-and violence-informed care in nursing education may also facilitate an understanding of the roots of health inequities and challenge the dominance of biomedical discourses (Browne et al., 2018; Levine et al., 2020). To move forward in the spirit of truth and reconciliation, a selfimplicated critique is necessary: we must be willing to critically examine "nursing's role within colonial health systems that have and continue to perpetuate harm", and consider how to forge a new path forward (Symenuk, Tisdale, Bourque Bearskin \& Munro, 2020).

\section{Conclusion}

Although epidemiological evidence suggests cancer disparities among FN Peoples in Canada are deeply concerning, these disparities cannot be glossed over and attributed to individual or lifestyle choices. Rather, they must be situated within the broader social, economic, historical, and political context. As we have argued, FN Peoples are faced with inequitable access to cancer care throughout the cancer journey, and significant gaps in cancer care remain; these 'spaces' can be traced to colonial ideologies and policies, challenging the disparities discourse. Although rarely considered within the context of cancer and cancer care, colonial ideologies and policies continue to have significant and tangible impacts on the lives of FN Peoples, influencing health and access to healthcare. Recognizing the impact of colonialism on access to healthcare and health outcomes among FN Peoples is a fundamental step towards health equity and should be of importance to nurses. Moreover, as a profession rooted in social justice values, and who daily bear witness to the impacts of inequities, nursing must question to what extent we have been complicit in perpetuating such colonial ideologies. Future research and clinical approaches to FN health must assess and address the entire context of FN Peoples' lives, including historical, socioeconomic and political influences on health and healing: "any approach that fails to consider Aboriginal peoples as active in response to their colonial situation, rather than simply passive victims, will fail to comprehend not only past changes in health status and healthcare, but also, and more importantly, the future direction that will be taken in these areas" [emphasis added] (Waldram et al., 2006, p. 295).

Ethical Permissions: Ethical approval was not required for this review and analysis.

Author Note: We have no known conflict of interest to disclose. 
The Canadian Journal of Critical Nursing Discourse

See it. Speak it. Write it. Change it.

\section{References}

Adelson, N. (2005). The embodiment of inequity. Canadian Journal of Public Health, 96(Supplement 2), S45-S61. https://doi.org/10.17269/cjph.96.1490.

Allan, B., \& Smylie, J. (2015). First Peoples, second class treatment: The role of racism in the health and wellbeing of Indigenous Peoples in Canada. www.wellesleyinstitute.com.

Anderson, J. M., Rodney, P., ReimerKirkham, S., Browne, A. J., Khan, K. B., \& Lynam, M. J. (2009). Inequities in health and healthcare viewed through the ethical lens of critical social justice: Contextual knowledge for the global priorities ahead. Advances in Nursing Science, 32(4), 282-294. https://doi.org/10.1097/ANS.0b013e31 81 bd6955.

Ashcroft, B., Griffiths, G., \& Tiffin, H. (1998). Key concepts in post-colonial studies. Routledge.

Assembly of First Nations. (2009). Access to cancer screening and First Nations. https://s22457.pcdn.co/wpcontent/uploads/2018/12/access_to_can cer_screening_first_nations_EN.pdf.

Barkwell, D. (2005). Cancer pain: Voices of the Ojibway people. Journal of Pain and Symptom Management, 30(5), 454-464.

https://doi.org/10.1016/j.jpainsymman. 2005.04.008

Battiste, M., \& Youngblood Henderson, J. (2012). Oppression and the health of Indigenous Peoples. In E. A. McGibbon (Ed.), Oppression: A social determinant of health (pp. 89-96). Fernwood

Publishing.
Browne, A. J. (2001). The influence of liberal political ideology on nursing science. Nursing Inquiry, 8(2), 118129. https://doi.org/10.1046/j.14401800.2001.00095.x

Browne, A. J. (2005). Discourses influencing nurses' perceptions of First Nations patients. Canadian Journal of Nursing Research, 37(4), 62-87.

Browne, A. J., Smye, V. L., \& Varcoe, C. (2005). The relevance of postcolonial theoretical perspectives to research in Aboriginal health. Canadian Journal of Nursing Research.

Browne, A. J., Varcoe, C., Ford-Gilboe, M., Nadine Wathen, C., Smye, V., Jackson, B. E., Wallace, B., Pauly, B., Herbert, C. P., Lavoie, J. G., Wong, S. T., \& Blanchet Garneau, A. (2018). Disruption as opportunity: Impacts of an organizational health equity intervention in primary care clinics. International Journal for Equity in Health, 17(154). https://doi.org/10.1186/s12939-0180820-2

Canadian Partnership Against Cancer. (2011a). First Nations, Inuit and Métis Action plan on cancer control. https://s22457.pcdn.co/wpcontent/uploads/2017/12/fnim-actionplan-cancer-control.pdf.

Canadian Partnership Against Cancer. (2011b). The future of cancer control in Canada.

https://www.partnershipagainstcancer.c a/wp-content/uploads/2017/08/thefuture-of-cancer-control-in-canadadiscussion-paper-on-pan-Canadiancancer-control-priorities-for-2012- 
The Canadian Journal of Critical Nursing Discourse

See it. Speak it. Write it. Change it.

2017.pdf.

Canadian Partnership Against Cancer. (2013). First Nations cancer control in Canada baseline report. https://s22457.pcdn.co/wpcontent/uploads/2017/12/first-nationscancer-control-baseline-report.pdf.

Canadian Partnership Against Cancer. (2015). Cancer stage in performance measurement: A first look.

https://www.partnershipagainstcancer.c a/wp-content/uploads/2019/01/Cancerstage-in-performance-measurementEN.pdf.

Cancer Care Ontario. (2002). Analysis of the findings: Aboriginal cancer care needs assessment. "It's Our Responsibility”... Aboriginal Cancer Care Unit Cancer Care Ontario.

http://govdocs.ourontario.ca/node/1952 8.

CancerCare Manitoba. (2013). The cancer story: Canadian cancer control in First Nations populations living off-reserve in rural, remote and isolated areas. https://dev.partnershipagainstcancer.ca/ wpcontent/uploads/2018/12/cancer_story_f irst_nations_off_reserve_EN.pdf

Cook, C. L. (2003). Jurisdiction and First Nations health and health care [unpublished master's thesis]. University of Manitoba.

de Leeuw, S. (2016). Activating place: Geography as a determinant of Indigenous Peoples' health and wellbeing. In M. Greenwood, S. de Leeuw, N. M. Lindsay, \& C. Reading (Eds.), Determinants of Indigenous Peoples' Health in Canada (pp. 90-103). Canadian Scholars' Press.
Decker, K. M., Demers, A. A., Kliewer, E. V, Biswanger, N., Musto, G., Elias, B., Griffith, J., \& Turner, D. (2015). Pap test use and cervical cancer incidence in First Nations women living in Manitoba. Cancer Prevention Research, 8(1), 49-55. https://doi.org/10.1158/19406207.CAPR-14-0277

Decker, K. M., Kliewer, E. V., Demers, A. A., Fradette, K., Biswanger, N., Musto, G., Elias, B., \& Turner, D. (2016). Cancer incidence, mortality, and stage at diagnosis in First Nations living in Manitoba. Current Oncology, 23(4), 225-232. https://doi.org/10.3747/co.23.2906

Demers, A. A., Decker, K. M., Kliewer, E. V, Musto, G., Shu, E., Biswanger, N., Fradette, K., Elias, B., Griffith, J., \& Turner, D. (2015). Mammography rates for breast cancer screening: A comparison of First Nations women and all other women living in Manitoba, Canada, 1999-2008. Preventing Chronic Disease, 12(E82). https://doi.org/10.5888/pcd12.140571

Elias, B., Kliewer, E. V., Hall, M., Demers, A. A., Turner, D., Martens, P., Hong, S. P., Hart, L., Chartrand, C., \& Munro, G. (2011). The burden of cancer risk in Canada's Indigenous population: A comparative study of known risks in a Canadian region. International Journal of General Medicine, 4, 699-709. https://doi.org/10.2147/IJGM.S24292

Erickson, B., Biron, V. L., Zhang, H., Seikaly, H., \& Côté, D. (2015). Survival outcomes of First Nations patients with oral cavity squamous cell carcinoma (Poliquin 2014). Journal of 
The Canadian Journal of Critical Nursing Discourse

See it. Speak it. Write it. Change it.

Otolaryngology - Head \& Neck

Surgery, 44(1).

https://doi.org/10.1186/s40463-015-

0056-8

Falk-Rafael, A. (2005). Speaking truth to power: Nursing's legacy and moral imperative. Advances in Nursing Science, 28(3), 212-223.

Falk-Rafael, A., \& Betker, C. (2012). Witnessing social injustice downstream and advocating for health equity upstream: "the trombone slide" of nursing. Advances in Nursing Science, 35(2), 98-112.

https://doi.org/10.1097/ANS.0b013e31 824fe70f

Fogarty, W., Lovell, M., Langenberg, J., \& Heron, M.-J. (2018). Deficit discourse and strengths-based approaches: Changing the narrative of Aboriginal and Torres Strait Islander health and wellbeing. Deficit discourse and strengths-based approaches. The Lowitja Institute. https://search.informit.com.au/documen tSummary; $=583838279439901$; res $=\mathrm{I}$ ELIND\#.XIDUwpHePd0.mendeley

Garvey, G., Cunningham, J., Mayer, C., Letendre, A., Shaw, J., Anderson, K., \& Kelly, B. (2020). Psychosocial aspects of delivering cancer care to Indigenous People: An overview. Global Oncology, 6, 148-154. https://doi.org/10.1200/JGO.19.00130

Hammond, C., Thomas, R., Gifford, W., Poudrier, J., Hamilton, R., Brooks, C., Morrison, T., Scott, T., \& Warner, D. (2017). Cycles of silence: First Nations women overcoming social and historical barriers in supportive cancer care. Psycho-Oncology, 26(2), 191198. https://doi.org/10.1002/pon.4335
Hart-Wasekeesikaw, F. (1996). First Nations peoples' perspectives and experiences with cancer [unpublished master's thesis]. University of Manitoba.

Horrill, T. C., Dahl, L., Sanderson, E., Munro, G., Garson, C., Fransoo, R., Thompson, G., Cook, C., Linton, J., \& Schultz, A. S. H. (2019b). Comparing cancer indidence, stage at diagnosis and outcomes of First Nations and all other Manitobans: A retrospective analysis. BMC Cancer, 19(1055). https://doi.org/10.1186/s12885-0196296-7

Horrill, T. C., Linton, J., Lavoie, J. G., Martin, D., Wiens, A., \& Schultz, A. S. H. (2019a). Access to cancer care among Indigenous Peoples in Canada: A scoping review. Social Science and Medicine, 238(112495). https://doi.org/10.1016/j.socscimed.201 9.112495

Horrill, T., Mcmillan, D. E., Schultz, A. S. H., \& Thompson, G. (2018). Understanding access to healthcare among Indigenous peoples: A comparative analysis of biomedical and postcolonial perspectives. Nursing Inquiry, 25(3). https://doi.org/10.1111/nin.12237

Kelm, M. (1998). Colonizing bodies: Aboriginal health and healing in British Columbia 1900-50. UBC Press.

Kurtz, D. L. M., Janke, R., Vinek, J., Wells, T., Hutchinson, P., \& Froste, A. (2018). Health sciences cultural safety education in Australia, Canada, New Zealand, and the United States: A literature review. International Journal of Medical Education, 9, 271-285. https://doi.org/10.5116/ijme.5bc7.21e2 
The Canadian Journal of Critical Nursing Discourse

See it. Speak it. Write it. Change it.

Lavoie, J.G., \& Forget, E. (2008). The cost of doing nothing: implications for the Manitoba health care system. Pimatisiwin: A Journal of Aboriginal and Indigenous Community Health, 6(1), 107-122.

Lavoie, J. G. (2013). Policy silences: Why Canada needs a national First Nations, Inuit and Métis health policy. International Journal of Circumpolar Health, 73(22690). https://doi.org/10.3402/ijch.v72i0.2269 0

Lavoie, J. G., Kaufert, J., Browne, A. J., Mah, S., O’Neil, J. D., Sinclair, S., \& Bluesky, K. (2015). Negotiating barriers, navigating the maze: First Nation peoples' experience of medical relocation. Canadian Public Administration, 58(2), 295-314. https://doi.org/10.1111/capa.12111

Lavoie, J. G., Forget, E. L., \& Browne, A. (2010). Caught at the crossroad: First Nations, health care, and the legacy of the Indian Act. Pimatisiwin: A Journal of Aboriginal and Indigenous Community Health, 8(1), 83-100.

Lavoie, J. G., Kaufert, J., Browne, A. J., \& O'Neil, J. D. (2016). Managing Matajoosh: Determinants of First Nations' cancer care decisions. BMC Health Services Research, 16(402). https://doi.org/10.1186/s12913-0161665-2

Levine, S., Varcoe, C., \& Browne, A. J. (2020). "We went as a team closer to the truth": Impacts of interprofessional education on trauma- and violenceinformed care for staff in primary care settings. Journal of Interprofessional Care. https://doi.org/10.1080/13561820.2019. 1708871

Loppie, C., \& Wien, F. (2005). Our journey: First Nations experience in navigating cancer care. Cancer Care Nova Scotia.

Maar, M., Burchell, A., Little, J., Ogilvie, G., Severini, A., Yang, J. M., \& Zehbe, I. (2013). A qualitative study of provider perspectives of structural barriers to cervical cancer screening among First Nations women. Women's Health Issues, 23(5), e319-e325. https://doi.org/10.1016/j.whi.2013.06.0 05

McGahan, C. E., Linn, K., Guno, P., Johnson, H., Coldman, A. J., Spinelli, J. J., \& Caron, N. R. (2017). Cancer in First Nations people living in British Columbia, Canada: an analysis of incidence and survival from 1993 to 2010. Cancer Causes and Control, 28(10), 1105-1116. https://doi.org/10.1007/s10552-0170950-7

McGibbon, E. (2016). Oppressions and access to health care: Deepening the conversation. In Dennis Raphael (Ed.), Social determinants of health: Canadian perspectives (3rd ed., pp. 491-520). Canadian Scholars' Press.

McGibbon, E., \& Lukeman, S. (2019). Critical social justice: The moral imperative for critical perspectives in nursing. Witness: The Canadian Journal of Critical Nursing Discourse, 1(1), 3-12. https://doi.org/10.25071/2291-5796.21

McGibbon, Elizabeth, Mulaudzi, F. M., Didham, P., Barton, S., \& Sochan, A. (2014). Toward decolonizing nursing: The colonization of nursing and 
The Canadian Journal of Critical Nursing Discourse

See it. Speak it. Write it. Change it.

strategies for increasing the counternarrative. Nursing Inquiry, 21(3), 179191. https://doi.org/10.1111/nin.12042

Metzl, J. M., \& Hansen, H. (2014).

Structural competency: Theorizing a new medical engagement with stigma and inequality. Social Science \& Medicine, 103, 126-133. https://doi.org/10.1016/j.socscimed.201 3.06 .032

Mitchell, T., Arseneau, C., \& Thomas, D. (2019). Colonial trauma: Complex, continuous, collective, cumulative and compounding effects on the health of Indigenous Peoples in Canada and beyond. International Journal of Indigenous Health, 14(5), 74-94. https://doi.org/10.32799/ijih.v14i2.3225 1

National Collaborating Centre for Aboriginal Health. (2011). Looking for Aboriginal health in legislation and policies, 1970 to 2008: The Policy Synthesis Project. National Collaborating Centre for Aboriginal Health. https://www.ccnsanccah.ca/495/Looking_for_Aboriginal_ health_in_legislation_and_policies,_19 $70-$

2008_The_policy_synthesis_project.n ccah?id $=28$.

Neal, R. D., Tharmanathan, P., France, B., Din, N. U., Cotton, S., Hamilton, W., \& Hendry, A. (2015). Is increased time to diagnosis and treatment in symptomatic cancer associated with poorer outcomes? Systematic review. British Journal of Cancer, 112, S92-107. https://doi.org/10.1038/bjc.2015.48

Nishri, E. D., Sheppard, A. J., Withrow, D. R., \& Marrett, L. D. (2015). Cancer survival among First Nations people of Ontario, Canada (1968-2007).
International Journal of Cancer, 136(3), 639-645. https://doi.org/10.1002/ijc.29024

Olson, R. A., Howard, F., Turnbull, K., Munroe, D., Zirul, C., Manji, R., Tobin, P., \& Ward, A. (2014). Prospective evaluation of unmet needs of rural and Aboriginal cancer survivors in Northern British Columbia. Current Oncology, 21(2), e179-85. https://doi.org/http://dx.doi.org/10.3747 /co.21.1729

Pauly, B. M., MacKinnon, K., \& Varcoe, C. (2009). Revisiting "who gets care?": Health equity as an arena for nursing action. Advances in Nursing Science, 32(2), 118-127. https://doi.org/10.1097/ANS.0b013e31 81a3afaf

Reading, C. (2015). Structural determinants of Aboriginal peoples' health. In M. Greenwood, S. de Leeuw, N. M. Lindsay, \& C. Reading (Eds.), Determinants of Indigenous Peoples' Health in Canada (pp. 3-15). Canadian Scholars' Press.

Reading, C. L., \& Wien, F. (2009). Health Inequalities and Social Determinants of Aboriginal Peoples ' Health. National Collaborating Centre for Aboriginal Health. https://www.ccnsanccah.ca/docs/determinants/RPTHealthInequalities-Reading-WienEN.pdf.

Sheppard, A. J., Chiarelli, A. M., Marrett, L. D., Mirea, L., Diane Nishri, E., \& Trudeau, M. E. (2010). Detection of later stage breast cancer in first nations women in Ontario, Canada. Canadian Journal of Public Health, 101(1), 101105. https://doi.org/10.1007/BF03405573 
The Canadian Journal of Critical Nursing Discourse

See it. Speak it. Write it. Change it.

Smith, L. T. (2005). Decolonizing methodologies: Research and Indigenous Peoples (2nd ed.). Zed Books.

Symenuk, P. M., Tisdale, D., Bourque Bearskin, D. H., \& Munro, T. (2020). In search of the truth: Uncovering nursing's involvement in colonial harms and assimilative policies five years post Truth and Reconciliation Commission. Witness: The Canadian Journal of Critical Nursing Discourse, 2(1), 84-96. https://doi.org/10.25071/2291-5796.51

The Saint Elizabeth First Nations Inuit and Métis Program. (2012). "Walk a Mile in My Moccasins": Foundations for action in First Nations cancer control. https://www.saintelizabeth.com/getmed ia/60380147-c3b4-492c-a437395e967ac4f0/Walk-a-Mile-in-MyMoccasins-Foundations-For-Action-inFirst-Nations-Cancer-Control.pdf.aspx

Thorne, S. (2014). Nursing as social justice: A case for emancipatory disciplinary theorizing. In P. N. Kagan, M. C. Smith, \& P. L. Chinn (Eds.), Philosophies and practices of emancipatory nursing: Social justice as praxis (pp. 79-90). Routledge. https://doi.org/10.4324/9780203069097

Tobias, J. K., Tinmouth, J., Senese, L. C., Jumah, N., Llovet, D., Kewayosh, A., Rabeneck, L., \& Dobrow, M. (2020). Health policy as a barrier to First Nations Peoples' access to cancer screening. Healthcare Policy, 15(3), 28-46. https://doi.org/10.12927/hcpol.2020.26 132

van Herk, K. A., Smith, D., \& Andrew, C.
(2011). Examining our privileges and oppressions: Incorporating an intersectionality paradigm into nursing. Nursing Inquiry, 18(1), 29-39. https://doi.org/10.1111/j.14401800.2011.00539.x

Vasilevska, M., Ross, S. A., Gesink, D., \& Fisman, D. N. (2012). Relative risk of cervical cancer in Indigenous women in Australia, Canada, New Zealand, and the United States: A systematic review and meta-analysis. Journal of Public Health Policy, 33(2), 148-164. https://doi.org/10.1057/jphp.2012.8

Wakewich, P., Wood, B., Davey, C., Laframboise, A., \& Zehbe, I. (2016). Colonial legacy and the experience of First Nations women in cervical cancer screening: A Canadian multicommunity study. Critical Public Health, 26(4), 368-380. https://doi.org/10.1080/09581596.2015. 1067671

Waldram, J. B., Herring, D. A., \& Young, T. K. (2006). Aboriginal health in Canada: Historical, cultural, and epidemiological perspectives (2nd ed.). University of Toronto Press.

Walker, L. M., \& Behn-Smith, D. (2015). Medicine is relationship, relationship is medicine. In M. Greenwood, S. de Leeuw, N. M. Lindsay, \& C. Reading (Eds.), Determinants of Indigenous Peoples' health in Canada (pp. 244 254). Canadian Scholars' Press.

Weitzel, J., Luebke, J., Wesp, L., Graf, M. D. C., Ruiz, A., Dressel, A., \& Mkandawire-Valhmu, L. (2020). The role of nurses as allies against racism and discrimination: An analysis of key resistance movements of our time. Advances in Nursing Science, 43(2), 
The Canadian Journal of Critical Nursing Discourse

See it. Speak it. Write it. Change it.

102-113.

https://doi.org/10.1097/ANS.00000000

00000290

Withrow, D. R., Pole, J. D., Diane Nishri, E., Tjepkema, M., \& Marrett, L. D. (2017). Cancer survival disparities between First Nation and non-Aboriginal adults in Canada: Follow-up of the 1991 census mortality cohort. Cancer Epidemiology Biomarkers and
Prevention, 26(1), 145-151. https://doi.org/10.1158/1055-9965.EPI16-0706

Yaphe, S., Richer, F., \& Martin, C. (2019). Cultural safety training for health professionals working in with Indigenous populations in Montreal, Quebec. International Journal of Indigenous Health, 14(1), 60-76. https://doi.org/10.32799/ijih.v14i1.3 